\title{
A Comparison Study Between English and Chinese Education Resources Distribution
}

\author{
Yiqing Liu $^{1, a}$
}

\author{
${ }^{1}$ Shenzhen College of International Education \\ ${ }^{a}$ Email:1205049713@qq.com
}

\begin{abstract}
With the progress towards the sustainable development goals, 'quality education,' as one of the goals, has generated great efforts from each country all over the world. This study attempts to compare the function of education resources distribution among developing and developed countries, in particular between China and the UK. It has been found that the UK has not only focused on basic education but also commit great efforts to higher education. The legitimated Chinese education system and the Compulsory Education Law of the People's Republic of China show greater effectiveness in enhancing the proportion of students participating in primary school education than in the UK. Besides, primary school education resources are distributed more equally among Chinese students than those in the UK.
\end{abstract}

Keywords: China, the UK, education resources distribution, sustainable development goals

\section{BACKGROUND}

International comparisons in education are of paramount importance to understand the recent developments in countries. According to Rikowaki (2002), the World Trade Organisation, and the World Bank, in order to increase productivity and economic growth, they increase global education by supporting global educational businesses. Halsey et al.(1961) suggest that in well-developed industrial countries, the education system establishes a solid connection with the economy. Besides, education has not only a close connection with economic growth, but it is also a vital tool for social solidarity. Emile Durkheim(1925) concludes that the major function of education is the transmission of society's norms and values. Education could be utilised to promote the connection between individuals and society, particularly the teaching of history. Children who have learned the history of their would eventually form a sense of commitment to their social group, achieving social solidarity.

In terms of the sustainable development goals published by the United Nations, by 2030, global citizens are to be ensured inclusive and equitable quality education and promote lifelong learning opportunities. This goal is recognised as one of urgent calls for action by all countries in developing and developed countries. Quality education is designed to guarantee inclusive and equitable quality education and promote lifelong learning opportunities for all. This goal supports reducing disparities and inequities in education, in terms of access as well as quality. There is a need to provide quality education for all, especially vulnerable populations, including the poor children, the children in rural areas, the disabled children, indigenous people, and refugee children.

China(the People's Republic of China), a single-party state governed by the Communist Party, is located in East Asia, whereas the United Kingdom(UK) is a sovereign country, comprising England, Wales, Scotland, and Northern Ireland, located in Western Europe. The UK government has published studies about the intercomparisons of the four countries in the UK; abundant research papers on comparisons with Chinese provinces are also available. However, no study is available considering the triangular comparison: international comparisons between China and the UK.

\subsection{World context}

In 2011, UNESCO (2014) estimated that the world's governments spent 5.1 percent of global Gross National Product (GNP) on education, up from 4.6 percent in 1999. The highest levels of spending were in North America and Western Europe, with 6.2 percent of regional GNP. The lowest levels of spending were in South and West Asia and sub-Saharan Africa. In its Global Education Monitoring Report, UNESCO (2018: 235-6) estimated 
that, of the $\$ 4.7$ trillion spent on education globally, 65 percent, or $\$ 3$ trillion, was spent in the high-income countries. Just 0.5 percent, or $\$ 22$ billion, was spent in the low-income countries, despite the school-age population being similar in both.

\subsection{The UK context}

The primary stage includes three age ranges: nursery (under 5), infant (5 to 7 or 8), and junior (up to 11 or 12), while in Scotland and Northern Ireland, there is mostly no distinction between infant and junior schools. In England, primary schools generally offer to 4-11-yearolds.

At the end of the primary stage of education, pupils normally need to take a range of external examinations. Generally, these are GCSE (General Certificate of Secondary Education) in England, Wales, and Northern Ireland and Standard Grades in Scotland, despite a range of other qualifications being available. For example, in Scotland, students study for the National Qualifications (NQ) Standard grade (a two-year course) and NQ Higher grade, requiring at least a further year of secondary schooling.

Higher education has developed quickly since the 1980s in the UK. In the 1950s, there were twenty-one universities in Britain; between 1945 and 1970, the system grew to be four times larger. Today, higher education has a 'standard coinage': a degree from Lancaster, Aberdeen or Bristol, at least in theory, is of the same standard as one from Cambridge or Oxford. In 2011 the UK government estimated that, in addition to degree awarding institutions, there were over 1,600 bodies, including 250 further education colleges, which currently offer some form of UK higher education provision.

In the UK the higher education sector massively expanded in terms of student numbers in the last quarter of a century. However, the distributional consequences led to an educational inequality: it has disproportionately benefited children from relatively rich families (Blanden et.al, 2014)

Since teacher salaries account for the bulk of school expenditure, the pupil teacher ratio is a reasonable proxy for school resources. Pupil-teacher ratio compares across countries at primary and secondary school: England and Wales are similar on this measure, although school funding generally is about $10 \%$ lower in Wales.4 However, across nations there are important differences in the funding mechanism. In England, most funding goes directly to schools based on funding formulae. However, in Wales, much of the funding is held back by local councils for central services (about one quarter of funding in 2006/07, as discussed by Reynolds 2008). The pupil-teacher ratio is lower in Scotland compared with the rest of the UK (by around $20-25 \%$ in primary schools). This is also reflected in other data on school expenditure, although there are doubts about its reliability (CPPR 2009). Finally, in Northern Ireland, the pupil-teacher ratio at primary school is similar to that in England and Wales, but the ratio for secondary schools is somewhat lower (though also higher than in Scotland).

\subsection{The Chinese context}

Great physical capital investments applied to a large stock of medium-skilled labor acquired before economic reforms fueled China's rapid growth. Witnessing the development, the demand for high-skilled labor has grown, and China has made substantial investments in producing it in the past decade. The egalitarian access to medium-skilled education characteristic of the prereform era has granted rise to considerable inequality in the access to higher education. Growth in China will be promoted by extending access to all levels of education, reducing barriers to the labor mobility, and developing the private sector.

Since the founding of New China, China's primary education has achieved the leapfrog development of education in big countries. From 1949 to 2018, China's gross enrolment rate in pre-school education increased from $0.4 \%$ (1950) to $81.7 \%$, the net primary school enrolment rate increased from $20 \%$ to $99.95 \%$, the gross enrolment rate in junior high schools increased from 3.1\% to $100.9 \%$, and the gross enrolment rate in upper secondary schools increased from $1.1 \%$ to $88.8 \%$.

In China, the gaokao or national college entrance examination largely determines an individual's access to higher education, in turn impacting on his or her future career choices and attainment of wealth, income, and social status.

2020 is the year of the 13th Five-Year Plan, during which the development of higher education in China has made remarkable achievements with the development of China's economy and society, and the gross enrolment rate of higher education has risen from $40 \%$ in 2015 to $54.4 \%$ today, successfully entering the stage of popularisation. According to the 2020 National Education Statistics, the total number of students enrolled in higher education at all levels in China will reach 41.83 million in 2020, with 9.6745 million students enrolled in the same year for the general college and 32.8529 million students in schools nationwide. In addition, 1.1066 million graduate students and 3.6376 million adults will be enrolled in 2020. In addition to the expansion of enrolment, the faculty has also increased significantly. The number of full-time teachers in ordinary colleges and universities is as high as 1.833 million. At the same time, there are 2,738 public higher education institutions in the country, including 1,270 undergraduate institutions (including 21 vocational schools at the undergraduate level) and 1,468 vocational or tertiary institutions. In terms of enrolment, number of students, number of 
teachers, or educational institutions, the higher education sector during the 13th Five-Year Plan period has achieved rapid development.

\section{DATA AND ANALYSIS}

\subsection{Differences in the opportunity of access to basic education between China and the UK}

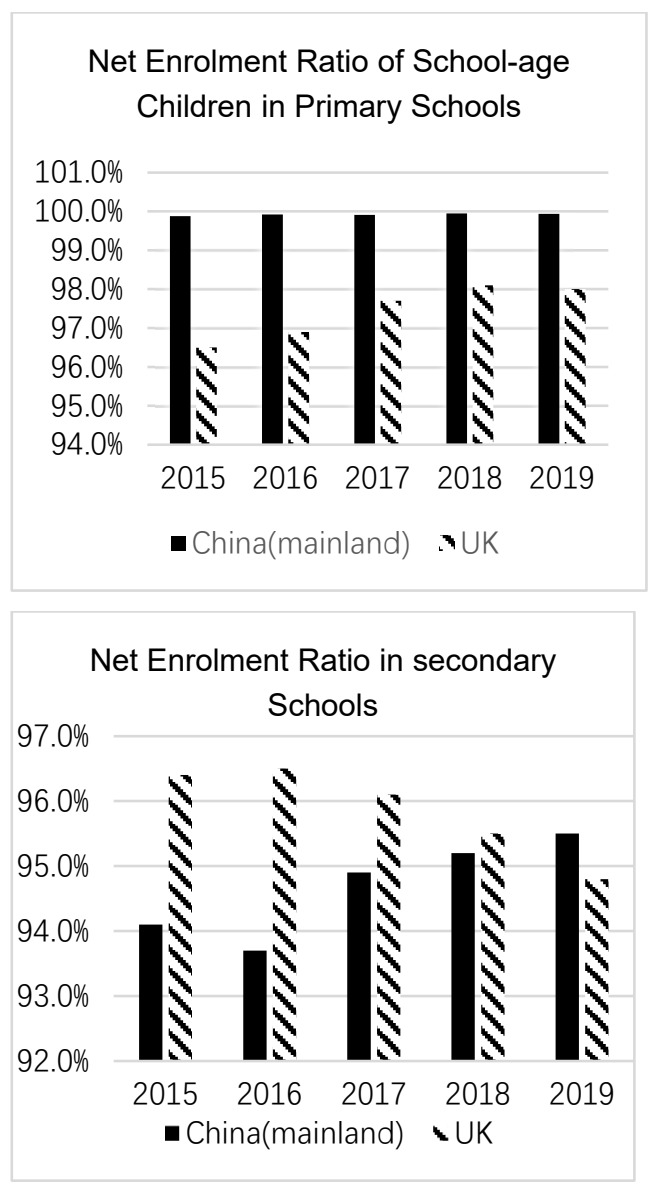

Figure 1 Net enrolment ratio in primary schools and secondary schools

One assessment instrument was designed to evaluate whether Chinese and English children could obtain basic education at their appropriate age. In this context, 'basic education' was defined as primary school and secondary school education. In China, entering primary school is six years old; as soon as students graduate from primary school, they might continue to enter 3 -year junior high school education.

Compulsory Education Law of the People's Republic of China states that China implements a nine-year compulsory education system, including 6-year primary school education and 3-year junior high school education. Therefore, as soon as students have completed the legitimated compulsory education, they need to take Senior High School Entrance Examination in order to get admitted into 3-year senior high school education. Similarly, in the UK, primary education begins when children are 5 to 6 years old; it is usual to transfer straight to secondary school at age 11 (in England, Wales, and Northern Ireland) or 12 (in Scotland).

Official statistics of school entrance rates were successfully collected from Chinese and British governments' published reports from 2015 to 2019. At the primary level, the net enrolment ratio of school-age children is $99.88 \%$ in 2015 . This is higher than the rate of the UK's (96.5\%). Besides, after five years, the promotion ratio of Chinese primary schools graduates even rises to $99.94 \%$. In the UK, $98 \%$ of applicants received an offer of primary schools, which is lower than Chinese, despite increasing by $1.5 \%$.

At the secondary level, in China, the enrolment rate of students entering senior high schools is $94.1 \%$ in 2015 ; in the following five years, the rate increased by $1.4 \%$ to $95.5 \%$. On the other hand, in the UK, \% made an offer of any preferred secondary school is $96.4 \%$ in 2015 , which is higher than the rate of China whereas, after five years, the percentage dropped to $94.8 \%$, reaching a lower percentage than Chinese statistics.3.2 Differences in the number of top universities between China and the UK.

At the primary level, both economies perform strongly, aiming for full participant rate of primary education of citizens; this is a positive sign for accomplishing the SDGs goal 'quality education' by 2030 .

\subsection{Differences in the total number of admission(fall) between China and the UK}

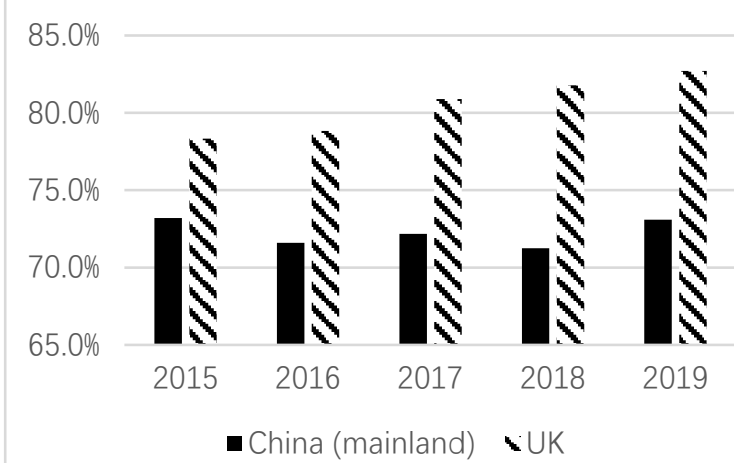

Figure 2 Total number of students from autumn admissions (fall) (2015-19)

As well as essential education matters, the issue of access to higher education needs to be considered. In this context, "higher education" is defined explicitly as undergraduate education at a higher level than secondary school. This is usually provided in different institutions such as universities. In China, the gaokao or national college entrance examination largely determines an individual's access to higher education, in turn impacting on his or her future career choices and attainment of wealth, income, and social status. 
However, the application process in the UK is different from Chinese: all UK universities' applications for full-time undergraduate courses are processed through UCAS (Universities and Colleges Admissions Service). Universities and colleges set their higher education courses' entry requirements and differ widely regarding and depending on the subject, specific courses, and the course s' provider. The entry requirements were set for each course to affirm students have the capability to complete the course successfully.

China has more than 6 million candidates receive an offer, while the UK only has over 400 thousand candidates annually. Although the admission quota in China is always more significant than the UK's, this is mainly because of its massive population. Until the end of 2019, the number of Chinese applicants exceeded 10 million, whereas the population of UK applicants was around 560 thousand. Therefore, I chose the ratio of the number of admissions and the total number of applicants(autumn) to explore the higher education resources distribution in the two countries.

In China, the total acceptance rate was $73.14 \%$ in 2015. The value fluctuates over the five years; until 2019, the acceptance rate is $73.09 \%$, seeing a slight decline. On the other hand, the total acceptance rate in the UK is $78.33 \%$ in 2015 , exceeding China by over $5 \%$. In 2019 , the total acceptance rate reached $82.71 \%$, surpassing China by more than $10 \%$.

The Secretary of the State in the UK suggests that "education systems in developing and conflict-affected countries are not consistently delivering quality education, leading to a learning crisis." On the other hand, the level of education in the developed countries performs better in terms of quality, proved by the statistics.

\subsection{Differences in the number of top universities between China and the UK}

Table 1. The number of top universities (2015-19)

\begin{tabular}{|l|l|l|}
\hline & China(mainland) & the UK \\
\hline 2015 & 11 & 58 \\
\hline 2016 & 12 & 58 \\
\hline 2017 & 12 & 59 \\
\hline 2018 & 14 & 58 \\
\hline 2019 & 17 & 58 \\
\hline
\end{tabular}

In terms of promoting high-quality talent, the academic performance of a university is of paramount importance. THE (Times Higher Education) ranks the universities internationally; the ranking is based on 13 carefully calibrated performance indicators that measure an institution's performance across four areas: teaching, research, knowledge transfer, and international outlook.

Are domiciles receive higher education? In this study, the proportion of the number of Top 500 to total population was a determining factor that influenced the opportunity of individuals to obtain a high-quality education. This may foster them to learn higher skills and more advanced technology, eventually contributing to a country's development that addresses the SDGs goals, driving an economy to sustainable development.

The total number of Top 500 universities in China was 11 in 2015 when the population is 1374620000 and increased to 17 by 2019 when the population is 1400050 000. At the same time, the number of Top 500 universities in the UK was 58 from 2015 to 2019, when its population increased from 65110000 to 67081000 . To present the data more numerically, the percentage of the top 500 universities/population is 100 times greater than China's.

This data pair could explain the previous comparison (3.2) why the admission rate to universities in the UK is higher than that of China.

\subsection{Differences in the expenditure on education between China and the UK}

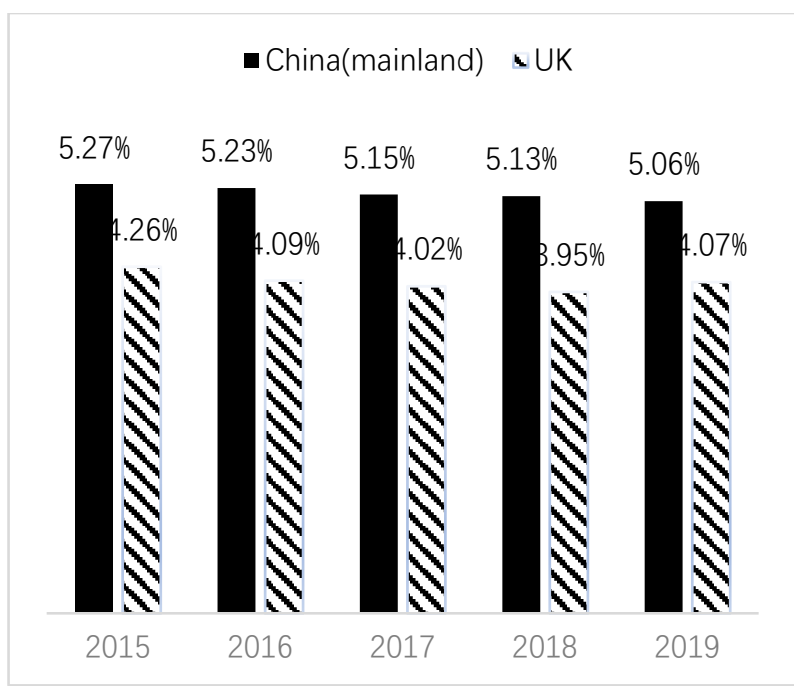

Figure 3 Public expenditure on education (\% of GDP)

In terms of promoting quality education, stakeholders, including households and government, have been generated great efforts.

To China, National Medium and Long-term Educational Reform and Development Plan Outline (2010-2020) clearly stated that by 2012, the national fiscal expenditure on education would reach the goal of 4\% of GDP. The Ministry of Education of the Peoples Republic in China emphasizes that educational investment is a fundamental and strategic investment that supports the country's long-term development, an essential material basis for the development of education, 
and the focus of public financial protection. The Party Central Committee and the State Council have always insisted on giving priority to education development, attaching great importance to increasing financial investment in education, and successively introduced a series of policy measures to increase financial investment in education.

Moreover to the UK, schools in England are set for a giant cash boost as the Prime Minister claims he will invest over $£ 14$ billion in primary and secondary education between 2019 and 2022/23. The percentage of public expenditure on education to GDP is utilized to reflect the allocation of wealth. The percentage fluctuated around 5\% in China, from $5.27 \%$ in 2015 to $5.06 \%$ in 2019. In the UK, the percentage also fluctuates, yet around $4 \%$ from $4.26 \%$ in 2015 to $4.07 \%$ in 2019 . Therefore, over five years, the public expenditure on education \% of GDP was consistently higher in China than in the UK.

This suggests that China, as one of the developing countries, is investing heavily in education, which goes along with the goal of SDGs' quality education, aiming to provide all students the opportunity to study in schools. The significant role of education could, later on, bring a positive impact to a country's economy by delivering well-educated elites to the society, enhancing the efficiency as well as productivity as a whole, thus accelerating the future development of the economy, resulting in a virtuous cycle.

\section{CONCLUSION}

The comparisons of educational resources distribution in England with that in China may be summarised as follows:

1 . The primary school education resources are distributed more equally among Chinese students than those in England. The legitimated Chinese education system, and the Compulsory Education Law of the People's Republic of China show greater effectiveness in enhancing the proportion of students participating primary school education than the UK.

2. There is a big stride forward in promoting enrolment into senior high school in China. This trend might be carried on in the future, following government's newly published development guidance 'the 14th Five-Year Plan', insist on putting education in the strategic position of priority development.

3. The UK has not only focused on basic education, but also commit great efforts into higher education. The Education Policy in the UK (2018) promoted the 12 years of quality education, so compared with that in China, an additional 3-year period is guaranteed among most English citizens as the policy conducted, which follows the sustainable development goals.

This analysis provides international perspectives that help encourage better education resources allocation. The research suggests that, with respects to basic education, China has achieved more equal educational resources distribution among persons; with respects to higher education, England performs excellently, promoting talents to experience advanced professional education. Two countries partially admit to the 'quality education', where China has nearly accomplished to provide education for all; England has ensured the quality of education. Therefore, both countries should continue to make great efforts towards 'quality education'

This research also provides insight of the different emphasis of the developed countries and the developing countries, and these can be demonstrated using data from provided official statistics. The developed countries such as England, value professional orientation education(universities), while the developing countries such as China, work towards ensuring everyone receives basic education.

Finally, some data resources are obtained from government published reports, including the admission quota, gross domestic product(GDP), expenditures on education and the enrolment rate in primary education, which have high reliability and comparability. As Miles and Irvine (1979) present their idea that "the data that official publications provide can be accessed nowhere but the state, the only institution in modern society with both the economic resources and political mandate to generate it in large quantities on a national scale," reflecting its uniqueness. However, official statistics are argued to be a social construction, as the result of particular subjective human decisions; the categories upon which the statistics are compiled are determined by the Government, and therefore may be open to change. The precise nature of the educational resources distribution in each country may vary while taking more factors into account, but many of the underlying patterns are the same. As such, the primary research of crosscountry education resources distribution comparison deserves much more attention than depending on secondary resources.

\section{REFERENCES}

[1] Haralambos, Michael, and Martin Holborn. Sociology : Themes and Perspectives. 8th ed., London, Collins, 2013.

[2] EDUCATION SYSTEM in the UK.

[3] Higher Education System of Uk. 
[4] Giddens, Anthony, and Phillip Sutton. Sociology. 9th ed., Cambridge, Polity, 2021.

[5] Blanden, Jo, and Stephen Machin. "Educational Inequality and the Expansion of UK Higher Education." Scottish Journal of Political Economy, vol. 51, no. 2, May 2004, pp. 230-249, 10.1111/j.0036-9292.2004.00304.x.

[6] Machin, Stephen, et al. "Educational Attainment across the UK Nations: Performance, Inequality and Evidence." Educational Research, vol. 55, no. 2, June 2013, pp. 139-164, 10.1080/00131881.2013.801242.

[7] Heckman, James, and Junjian Yi. Human Capital, Economic Growth, and Inequality in China. May 2012, 10.3386/w18100. Accessed 21 Aug. 2021.

[8] "70 Years of Basic Education Reform and Development in New China-Ministry of Education of the People's Republic of China." Www.moe.gov.cn, www.moe.gov.cn/jyb_xwfb/s5147/201909/t201909 26 401046.html.

[9] Wang, Houxiong. "Access to Higher Education in China: Differences in Opportunity." Frontiers of Education in China, vol. 6, no. 2, 19 May 2011, pp. 227-247, 10.1007/s11516-011-0130-6.

[10] Luo, Xinyuan. “The Development Process, Status Quo and Challenges of China's Higher Education CNKI." Kns.cnki.net, 23 July 2021, kns.cnki.net $/ \mathrm{kcms} /$ detail/detail.aspx?FileName $=\mathrm{XA}$ LH202103013\&DbName=CJFQTEMP.

[11] "Compulsory Education Law of the People's Republic of China." Www.npc.gov.cn, www.npc.gov.cn/npc/c30834/201901/21b0be5b97e 54c5088bff17903853a0d.shtml. Accessed 21 Aug. 2021.

[12] "UCAS Undergraduate Entry Requirements." UCAS, 13 Oct. 2014, www.ucas.com/undergraduate/what-and-wherestudy/ucas-undergraduate-entry-requirements.

[13] Gov.UK. "DFID Education Policy." GOV.UK, 6 Mar. 2018 , www.gov.uk/government/publications/dfideducation-policy-2018-get-children-learning/dfideducation-policy.

[14] "World University Rankings." Times Higher Education (THE), 20 Aug. 2019, www.timeshighereducation.com/world-universityrankings/2020/world-ranking\#.

[15]"Opinions of the State Council on Further Increasing Financial Investment in Education - Government
Portal of the Ministry of Education of the People's Republic of China."Www.moe.gov.cn, www.moe.gov.cn/jyb_xxgk/moe_1777/moe_1778/ 201107/t20110701_121857.html. Accessed 21 Aug. 2021.

[16]"Education $\quad$ Policy." GOV.UK, www.gov.uk/government/publications/dfideducation-policy-2018-get-children-learning/dfideducation-policy\#fn:5. Accessed 21 Aug. 2021.

[17] Laker, Collin. "The Social Construction of Official Statistics." Curriculum Press, curriculumpress.co.uk/resources/the-social-construction-ofofficial-statistics. Accessed 26 Aug. 2021. 